\title{
Evidence of Altered Polyamine Concentrations in Cerebral Cortex of Suicide Completers
}

\author{
Gary Gang Chen', Laura M Fiori', Luc Moquin², Alain Gratton², Orval Mamer ${ }^{3}$, Naguib Mechawar' \\ and Gustavo Turecki*,' \\ 'McGill Group for Suicide Studies, Douglas Mental Health University Institute, McGill University, Montreal, Québec, Canada; ${ }^{2}$ Research Center, \\ Douglas Mental Health University Institute, Montreal, Québec, Canada; ${ }^{3}$ Mass Spectrometry Unit, McGill University, Montreal, Québec, Canada
}

\begin{abstract}
Recent studies have implicated alterations in the expression of polyamine-related genes in the brains of suicide completers including widespread downregulation of spermidine/spermine $\mathrm{NI}$-acetyltransferase, the key enzyme in polyamine catabolism, suggesting compensatory mechanisms attempting to increase brain levels of polyamines. Given the complexity of the polyamine system, quantification of the levels of the polyamines is an essential step in understanding the downstream effects of dysregulated gene expression. We developed a method using high-resolution capillary gas chromatography (GC) in combination with mass spectrometry (MS) for quantitation of polyamines from post-mortem brain tissue, which allowed us to accurately measure spermidine and putrescine concentrations in post-mortem brain tissues. Using this method, we analyzed putrescine and spermidine levels in a total of I 26 samples from Brodmann areas 4, 8/9, and II, from 42 subjects, comprising 16 suicide completers with major depression, 13 non-depressed suicide completers, and 13 control subjects. Both putrescine and spermidine levels fell within the expected nanomolar ranges and were significantly elevated in the brain of suicide completers with a history of major depression as compared with controls. These results were not accounted by possible confounders. This is the first GC-MS study to analyze the expression of putrescine and spermidine from post-mortem brain tissue and confirms the hypothesis raised by previous studies indicating alterations in putrescine and spermidine levels in suicide/major depression.

Neuropsychopharmacology (2010) 35, 1477-1484; doi:I0.1038/npp.2010.17; published online 3 March 2010
\end{abstract}

Keywords: polyamines; putrescine; putrescine-D4; spermidine; suicide; gas chromatography-mass spectrometry

\section{INTRODUCTION}

Suicide is a major public health issue. The risk for suicide is believed to be the result from a combination of social, environmental, and genetic factors. Neurobiological studies have implicated several neurotransmitter systems in suicide, and while the traditional focus has been on monoaminergic transmission, recent evidence also suggests a role for the polyamine system in suicide and other psychiatric disorders (Fiori and Turecki, 2008; Guipponi et al, 2008; Karssen et al, 2007; Sequeira et al, 2006).

Polyamines, including putrescine (1,4-diaminobutane, PUT), spermidine ( $N$-[3-aminopropyl]-1,4-diaminobutane, $\mathrm{SPD})$, and spermine ( $N, N$-bis[3-aminopropyl]-1,4-diaminobutane, SPM), are low molecular weight aliphatic amines that have essential roles in living organisms (Casero and Pegg, 2009; Igarashi and Kashiwagi, 2009; Pegg, 2009; Wallace et al, 2003). In mammals, polyamines are involved

*Correspondence: Dr G Turecki, McGill Group for Suicide Studies, Douglas Mental Health University Institute, 6875 LaSalle Boulevard, Verdun, Quebec H4H IR3, Canada, Tel: + I 514 76I 6131×2369, Fax: + | 5l4 762 3023, E-mail: gustavo.turecki@mcgill.ca Received 9 October 2009; revised I February 2010; accepted । February 2010 in many physiological functions including cell proliferation and apoptosis (Igarashi et al, 1975; Marton and Pegg, 1995; Seiler and Raul, 2005), immunity (Seiler and Atanassov, 1994), and oxidative stress response. Brain polyamines are largely stored in astrocytes and synaptic vesicles and this distribution may confer polyamines regulatory activities to a variety of receptors located on the surface of glia and neurons (Belle et al, 2004; Lovaas and Carlin, 1991; Masuko et al, 2003; Takano et al, 2005). In particular, the ability of the polyamines to modulate transmission through $\mathrm{N}$-methyl-D-aspartate (NMDA) receptors and alpha-amino3-hydroxy-5-methylisoxazole-4-propionic acid (AMPA) receptors have been well established (Kashiwagi et al, 1997; Kelly et al, 2009; Masuko et al, 2003; Rock and Macdonald, 1995). Polyamines have also been shown to influence the function of gamma amino-butyric acid (GABA) receptors (Gilad et al, 1992). Changes in the expression of the polyamines and their metabolic enzymes have been found in many pathological and psychiatric conditions, including schizophrenia (Ramchand et al, 1994; Svinarev, 1986), mood disorders (Genedani et al, 2001; Zomkowski et al, 2006), stress and anxiety (Gilad and Gilad, 2002; Sohn et al, 2002), and suicidal behaviors (Guipponi et al, 2008; Karssen et al, 2007; Sequeira et al, 2006, 2007). 
Studies by our group, using post-mortem brain tissues from suicide completers, have identified alterations in the expression of a number of polyamine-related genes using complementary methodologies, particularly spermidine/ spermine N1-acetyltransferase (SAT1), which was found to be downregulated in suicide completers both with and without major depressive disorder (Klempan et al, 2009; Sequeira et al, 2006, 2007). This is consistent with data produced by other groups in both human and animal model studies (Guipponi et al, 2008; Karssen et al, 2007). As alterations in the expression of SAT1, as well as other polyamine genes, suggests compensatory changes aiming at increasing the availability of polyamines, we hypothesized that the levels of spermine, spermidine, and putrescine would be different in suicide completers compared with controls. To this end, this study aimed at directly measuring levels of two of these polyamines, specifically spermidine and putrescine, in brain tissues derived from suicide completers and controls.

Early analytical methods to measure polyamine concentrations were based on high performance liquid chromatography (HPLC) or gas chromatography (GC) alone. These methods have limitations regarding specificity, which becomes an important issue when only peak retention times are used for detection, as compounds with similar properties may co-elute or produce overlapping peaks. This is not a concern in mass spectrometry (MS), and when combined with GC, one of the most powerful analytical systems becomes available (GC-MS). In recent years, GCMS has been used for polyamine analysis in simple biological samples, such as hair (Li et al, 2008), urine (Paik et al, 2006), and plasma (Paik et al, 2007). However, a GCMS method for analyses of the major polyamines from brain samples was not available. We have recently developed a specific GC-MS method for measurement of spermidine and putrescine from post-mortem cerebral cortex (Chen et al, 2009). Although measurement of spermine by GC-MS has been shown from some biological samples, such as hair and urine (Li et al, 2008; Paik et al, 2006), GC-MS quantification of spermine simultaneously with putrescine and spermidine is methodologically challenging in postmortem brain tissues, and requires a separate methodology. Therefore, this study aimed at quantification of putrescine and spermidine in cerebral cortex derived from suicide completers and controls.

\section{MATERIALS AND METHODS}

\section{Subjects and Diagnostic Procedures}

Our sample consisted of 42 male subjects of FrenchCanadian origin. We opted for an only-male sample to avoid gender-related heterogeneity. Controls died either in accidents $(30 \%)$ or by natural death $(70 \%)$, whereas suicides died by hanging $(70 \%)$, carbon monoxide $(12 \%)$, selfinflicted wounds $(12 \%)$, or by other methods $(6 \%)$. Postmortem brain tissues were obtained from the Quebec Suicide Brain Bank (QSBB) (www.douglasrecherche.qc.ca/ suicide), in which they were processed and dissected at $4{ }^{\circ} \mathrm{C}$, and snap-frozen in liquid nitrogen before storage at $-80^{\circ} \mathrm{C}$, following standard procedures (Bird and Vonsattel, 1993). All subjects collected by the QSBB have to have died suddenly without a prolonged agonal period. Brain tissue dissection was performed following standard procedures and anatomical landmarks (Mai et al, 2007; Nolte, 2002). Specifically, we focused on Brodmann areas (BA) 4 , $8 / 9$, and 11 , which were the brain regions used in our original report indicating SAT1 differential expression in suicide (Sequeira et al, 2006). The following anatomical landmarks were used to identify these brain regions. BA4: precentral gyrus. As this BA region is located anterior to the central gyrus, the latter was used as landmark for the dissections. BA8-9: BA8 occupies mainly a portion of the superior frontal gyrus delimited, medially, by the cingulate sulcus, and laterally, by the superior frontal sulcus. BA9 occupies also part of the superior frontal gyrus, as well as part of the middle frontal gyrus. It is more anterior and ventral than BA8, extending medially from the cingulate sulcus, and laterally, to the inferior frontal sulcus. As the exact macroscopic boundaries between BA8 and BA9 are imprecise, we have opted to use tissue from both regions combined as BA8/9. In this study, we used tissue dissected from the superior frontal gyrus, dorsally to the frontal pole, to avoid dissecting tissue from BA10. BA11: this BA region occupies a large portion of the orbital gyrus and straight (rectus) gyrus. Tissue for this study was dissected from the orbital gyrus.

Psychiatric diagnoses were obtained using the psychological autopsy method with the Structured Clinical Interview for DSM-IV Axis I (SCID-I) (First et al, 2001), as described elsewhere (Dumais et al, 2005). Written informed consent was obtained for all subjects from next of kin. This study was approved by our local institutional review board.

\section{Study Design}

Putrescine and spermidine concentrations in post-mortem cerebral cortex tissues were analyzed using a specialized polyamine extraction and detection method, which involved high-resolution capillary GC in combination with MS (Chen et al, 2009). We collected putrescine and spermidine measurements from 126 brain samples obtained from 42 subjects across three different brain regions as indicated above. The 42 subjects consisted of 16 suicide subjects with major depression (SMD), 13 suicide subjects without major depression (NDS), and 13 control subjects (C). Cases and controls were matched for age, $\mathrm{pH}$, and post-mortem interval (PMI). Methods of suicide were similarly distributed between both suicide groups. We considered individuals as having a history of active treatment if they had a 6-month history of psychotropic prescription and/or had a positive toxicology result.

\section{GC-MS Measurement of Putrescine and Spermidine from Post-Mortem Cerebral Cortex}

GC-MS method for analysis putrescine and spermidine. A dedicated GC-MS method was developed for extraction and quantification of putrescine and spermidine from postmortem human brain tissue (Chen et al, 2009). This method is based on the ethoxycarbonyl (EOC) reaction of amino functions combined with subsequent trifluoroacetyl (TFA) 
derivatization. Electron ionization GC-MS with selected ion monitoring (SIM) techniques were used with [2,2,3,3-2H4]1,4-diaminobutane (putrescine-D4) as the internal standard for endogenous putrescine, and 1,7-diaminoheptane as the internal standard for spermidine. This method allows accurate quantitation of spermidine and putrescine down to nanogram levels per gram of wet brain tissue. The isolation methodology is robust and requires less work and time than many previous methods. Before analysis of brain samples, authentic polyamines used as calibration standards were measured, and calibration curves for each target analyte was plotted. A total ion current chromatogram for the derivatives of putrescine and spermidine as well as the internal standard 1.7-diaminoheptane, is given in Figure 1a. A selected ion chromatogram for putrescine and spermidine, extracted from the cerebral cortex of a normal brain and one from a suicide victim with spiked internal standards, 1,7-diaminoheptane, is shown in Figure $1 b$.

GC-MS conditions. An Agilent bench-top HP6890/ MSD5973N Chemstation system (Agilent Technologies, Santa Clara, CA) was used for this work. Electron ionization (EI, $70 \mathrm{eV}$ ) was used in full scan and SIM modes for all measurements. The helium flow rate and column head pressure were set to $1.0 \mathrm{ml} / \mathrm{min}$ and 8.5 p.s.i., respectively. Sample aliquots of $2 \mu \mathrm{l}$ were injected in splitless mode followed by a 5-min solvent delay. An HP-5MS capillary column ( $25 \mathrm{~m}, 0.25 \mathrm{~mm}$ i.d., and $0.25 \mu \mathrm{m}$ thickness) was used for analysis and was programmed from 140 to $210^{\circ} \mathrm{C}$ at $8{ }^{\circ} \mathrm{C} / \mathrm{min}$ followed by a 2 -min hold, then at $20^{\circ} \mathrm{C} / \mathrm{min}$ to $300^{\circ} \mathrm{C}$, followed by a 4 -min hold. The column was baked out at $320^{\circ} \mathrm{C}$ for $4 \mathrm{~min}$. Instrument temperatures were: source $200^{\circ} \mathrm{C}$, quadrupole sector $150{ }^{\circ} \mathrm{C}$, interface $250{ }^{\circ} \mathrm{C}$, and injector $260^{\circ} \mathrm{C}$. The typical source pressure was $1.8 \times 10^{-5}$ torr. Full scans at $2.0 \mathrm{~s} / \mathrm{scan}$ were over the mass range $\mathrm{m} / \mathrm{z} 10-700$.

\section{Data Analysis}

GC-MS data analysis was carried out with Chemstation software (Agilent Technologies). Statistical analyses were performed using SPSS 15.0. Pearson correlations were used to assess relationships between sample characteristics and polyamine levels. Univariate two-way ANOVA tests with Bonferroni post hoc comparisons were used for the analysis of spermidine and putrescine differences. The two factors analyzed were group (C, NDS, SMD) and BA. Covariates considered were age, $\mathrm{pH}, \mathrm{PMI}$, comorbidity with substance, and toxicology/psychotropic treatment history. Age, $\mathrm{pH}$, and PMI were entered in the ANOVA models as covariates. Comorbidity with substance was controlled for by running an ANOVA using this information as a grouping variable.

\section{RESULTS}

\section{Clinical and Demographic Features}

Table 1 lists the demographic and clinical characteristics of the subjects included in this study, according to groups.
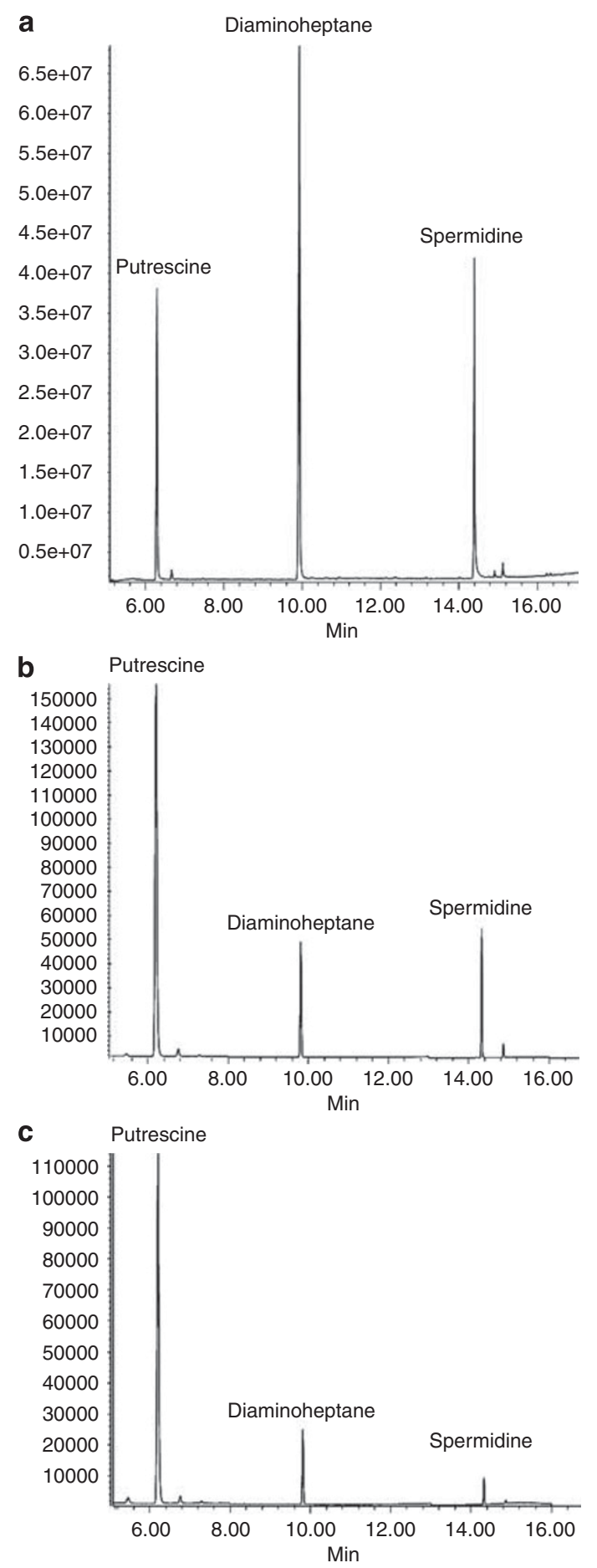

Figure I GC-MS spectra of polyamines and internal standards. (a) Total ion current $(\mathrm{TIC})$ chromatogram for the derivatives of the authentic amines, putrescine, and spermidine, as well as the internal standard diaminoheptane, used in the study. (b, c) Composite selected ion chromatograms (SIM) for putrescine, spermidine, and the internal standard diaminoheptane isolated from the cortex of a suicide completer (b) and a control subject (c).

SMD and DNS cases, as well as controls, had similar demographic characteristics, with no significant differences in age, PMI, or $\mathrm{pH}$. 
Table I Demographic and Clinical Characteristics of the Subjects Included in this Study According to Group

\begin{tabular}{|c|c|c|c|}
\hline Group & C & NDS & SMD \\
\hline $\bar{N}$ & 13 & 13 & 16 \\
\hline Age (years) & $37.15 \pm 11.48$ & $31.92 \pm 8.20$ & $36.38 \pm 11.58$ \\
\hline PMI (h) & $26.15 \pm 4.43$ & $34.38 \pm 23.77$ & $25.87 \pm 6.75$ \\
\hline $\mathrm{pH}$ & $6.45 \pm 0.30$ & $6.48 \pm 0.33$ & $6.53 \pm 0.25$ \\
\hline MDD & - & - & $100 \%(16 / 16)$ \\
\hline Substance dependence & - & 15.38\% (2//3) & $25 \%(4 / 16)$ \\
\hline Positive toxicology for psychotropics & - & $15.38 \%(2 / 13)^{\mathrm{a}}$ & $18.75 \%(3 / 16)^{b}$ \\
\hline$R x$ & - & $7.69 \%(1 / 13)^{c}$ & $6.25 \%(2 / 16)^{d}$ \\
\hline
\end{tabular}

${ }^{\mathrm{a} A l c o h o l .}$

${ }^{\mathrm{b} C l o m i p r a m i n e, ~ a l c o h o l, ~ a n d ~ c o c a i n e . ~}$

'Benzodiazepinic $R \times$.

'TCA and SSRI.

\section{Analysis of Putrescine, Spermidine, and Spermine Levels}

Representative mass spectra are shown in Figure 1. Levels of either polyamine were within the expected nanomolar ranges, with significant variability between brain regions. Although in principle spermine can be quantified using the method we developed (Chen et al, 2009), it is methodologically challenging to measure concurrently all three major polyamines. Spermine was at the limit of detection in the analyses conducted in this study and accurate measurement was not possible. Therefore, in this study, we focused on the analyses of putrescine and spermidine.

For putrescine, mean values (SD) were $1.84(0.82), 3.59$ (3.4), and 1.25 (0.33), respectively for BA $4,8 / 9$, and 11 $(\mathrm{F}=14.65, \mathrm{df}=2,113 ; P<0.001)$; and for spermidine, mean values (SD) were 6.99 (6.27), 4.91 (4.90), and 4.39 (3.21), also respectively for $\mathrm{BA} 4,8 / 9$, and $11(\mathrm{~F}=2.85, \mathrm{df}=2,113$; $P=0.06$ ). Levels for either putrescine or spermidine were not correlated with age, PMI, or $\mathrm{pH}$, for any of the brain regions examined ( $r$ range from -0.095 to 0.017 ; all $P>0.3$ ).

The results for putrescine and spermidine per group and brain region are depicted in Figure 2. We found significantly different levels of putrescine $(\mathrm{F}=6, \mathrm{df}=2,113$; $P=0.003)$ and spermidine $(\mathrm{F}=3.0, \mathrm{df}=2,113 ; P=0.05)$ between groups. Both putrescine $(P=0.002)$ and spermidine $(P=0.05)$ levels were significantly higher in Bonferroni adjusted post hoc comparisons between SMD and controls, but not between NDS suicides and controls or between the two suicide groups. None of these differences could be explained by the effect of $\mathrm{pH}$, PMI, age, substance comorbidity, or psychotropic treatment, as none of these covariates were significant. For putrescine, there were no significant effects for region or region by group interaction. For spermidine, there were significant effects for region $(\mathrm{F}=2.85 ; \mathrm{df}=2,113 ; P=0.048)$, but not for group by region interaction.

\section{DISCUSSION}

Using a GC-MS method specifically designed for measuring polyamine concentrations in post-mortem brain tissues, we

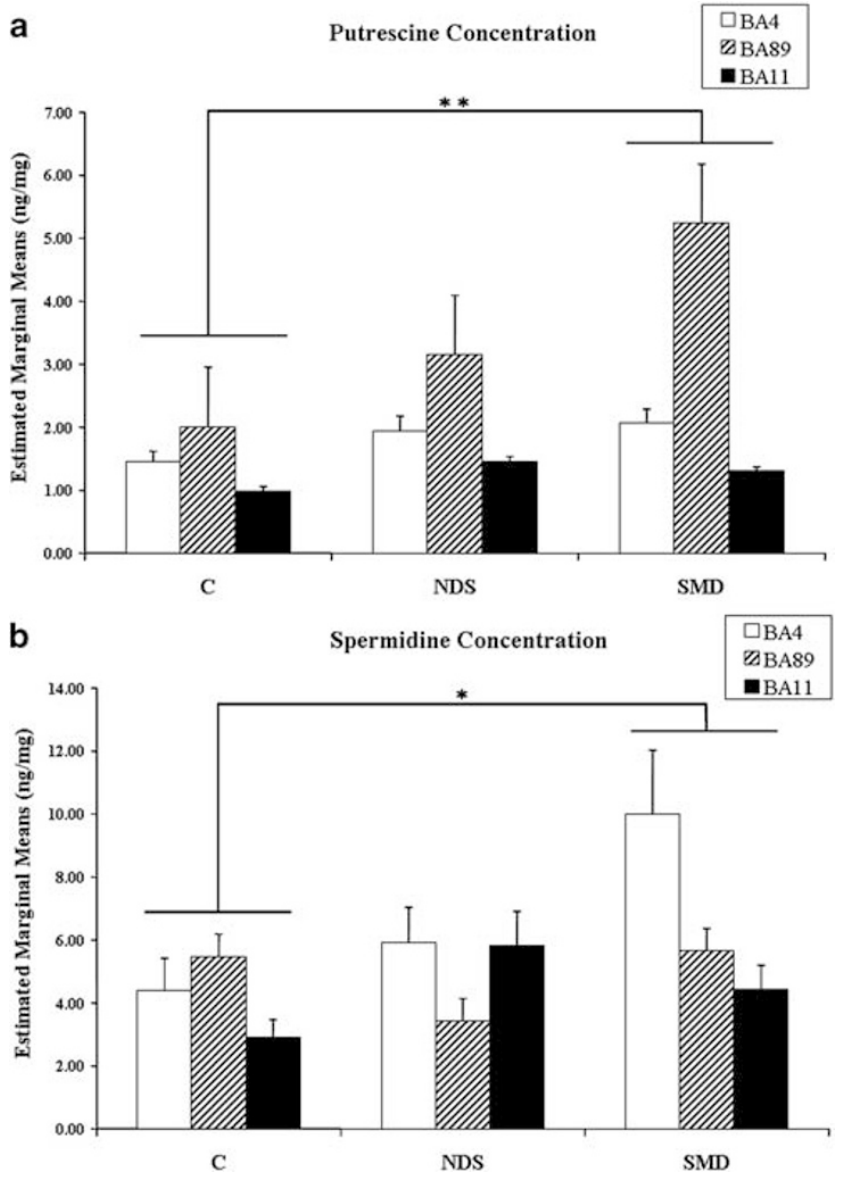

Figure 2 (a) Putrescine and (b) spermidine levels in post-mortem brain tissues. Concentrations (ng/mg tissue) + SEM were obtained from controls (C), suicide completers without major depressive disorder (NDS), and suicide completers with major depressive disorder (SMD). $* P \leqslant 0.05$; *** $P \leqslant 0.01$.

have successfully determined putrescine and spermidine levels in three different brain regions obtained from 42 suicide completers and control subjects. We found significant increases in putrescine and spermidine levels, 
which were explained primarily by differences between the SMD suicides and controls. Although we found no significant difference between the two suicide groups (NDS vs SMD), this may be a result of insufficient power, and we therefore cannot rule out the possibility that differences do exist. Future experiments should be performed with more subjects to clarify this effect.

Our findings are in agreement with our previous studies showing decreased SAT1 expression in suicide completers at both mRNA and protein levels (Klempan et al, 2009; Sequeira et al, 2006). SAT1 is the rate-limiting enzyme in polyamine interconversion and a key regulator of cellular polyamine concentrations. Acetylation of spermine and spermidine by SAT1 is followed by oxidative deamination by polyamine oxidase (PAO) to produce spermidine and putrescine, respectively, as well as 3-acetamidopropanal and hydrogen peroxide (Bolkenius and Seiler, 1981). The increased levels of spermidine observed in this study may thus be a consequence of decreased SAT1 expression, resulting in the accumulation of spermidine, and possibly spermine. Elevated levels of the polyamines, particularly putrescine, are an important component of the polyamine stress response (PSR), which has been implicated in the detrimental effects of stress and anxiety, as well as the development of other psychiatric disorders (Gilad and Gilad, 2003; Sohn et al, 2002). Our findings of elevated putrescine and spermidine levels may therefore indicate a role for the PSR in the neurobiology of depression and suicide.

It has been shown that polyamines modulate learning and memory by interacting with the polyamine-binding site at the NMDA and AMPA glutamate receptors (Kashiwagi et al, 1997; Kelly et al, 2009; Velloso et al, 2009). NMDA receptors and AMPA receptors have distinct roles in controlling synaptic plasticity: AMPA receptors effect short-term changes in synaptic strength, whereas NMDA receptors regulate genes that are required for the long-term maintenance of these changes (Groc and Choquet, 2006; Rao and Finkbeiner, 2007). Dysfunction of NMDA and AMPA receptors have been implicated in a verity of neurological disorders, such as Parkinson's disease (Loschmann et al, 1997; O'Neill and Witkin, 2007), Alzheimer's disease (Carlson et al, 1993; Chang et al, 2006; Wang et al, 2009), schizophrenia (Bennett, 2009; Halene et al, 2009; Seillier and Giuffrida, 2009), anxiety and depression (Ireland and Abraham, 2009; Kielland and Heggelund, 2002; Li et al, 2004; Ryan et al, 2009; Szewczyk et al, 2009), and suicidal behaviors (Freed et al, 1993; Nowak et al, 2003; Tzschentke, 2002). It has been shown that different levels of the polyamines spermidine and spermine have distinct effects on NMDA receptor activity. Low levels of spermidine and spermine can attenuate glutamate-induced neurotoxicity by enhancing the binding of ion channel blockers; while high levels of spermidine and spermine have enhanced glutamatergic effects (Bence et al, 2000). AMPA receptors are a subtype of the ionotropic glutamate receptors that mediate fast synaptic transmission in the central nervous system and have key roles in memory formation (Sanderson et al, 2008). The mechanism of polyamine binding and action on AMPA receptors has been extensively studied using polyamine-based ligands (Jensen et al, 2006; Stromgaard and Mellor, 2004). Recently, it has been found that a subclass of AMPA receptors lacking the GluR2 subunit is susceptible to blockage by polyamines in a voltagedependent manner, implicating polyamines in modulation of neurotransmission (Kelly et al, 2009). Therefore, the changes in polyamine content we observed in this study may have significant influences on neuronal activity, such as those related to synaptic plasticity and associated with anxiety, depression, and suicidal behaviors (Fiori and Turecki, 2008).

Analysis of brain polyamine levels in suicide completers has previously been reported by Gilad et al using HPLC (Gilad et al, 1995). They did not identify any significant differences in polyamine concentrations between suicide completers and control subjects. Many factors may have contributed to these differences. First, all our subjects are male and come from a genetically homogenous population, whereas the sample from the previous study comprised both males and females, and was derived from a general population. Our use of only male subjects may be particularly important as gender-specific differences in levels of polyamines and their metabolic enzymes, as well as responses to polyamine exposure have been observed (Barron et al, 2008; Bastida et al, 2007; Ferioli et al, 1999; Gilad et al, 2002). Our use of a more homogenous population may have made the group differences more easily detectable, or alternatively, our results may reflect differences in polyamine metabolism between populations. More importantly, however, the previous study used HPLC, which has inherent issues with specificity, as compounds with similar properties may elute at the same time or produce overlapping peaks with the compounds of interest. This problem is especially apparent in complex biological samples such as brain tissues. Indeed, we detected the presence of numerous other bioamines with similar properties to the polyamines. These bioamines may not have been distinguished from the compounds of interest had only peak retention times been used. Finally, differences in PMI or polyamine extraction procedures may also account for some of the differences in findings.

Although our GC-MS method allowed us to successfully quantify putrescine and spermidine, we were unable to measure spermine, the largest polyamine compound. Each GC-MS derivatization and analytical method can only quantify a limited number of compounds with similar properties. Concurrent quantification of the three major polyamines together was challenging in relatively simpler biological samples such as hair (Choi et al, 2000; Li et al, 2008). The difficulty for quantification of spermine is mainly because of the presence of hiding active hydrogen atoms in its two secondary amine groups. Although our method is capable of accurately and efficiently quantifying putrescine and spermidine, the ability to concurrently detect spermine is compromised because of sample complexity and the derivatization conditions used. Consequently, spermine was at the limit of detection and accurate measurement in the majority of brain samples analyzed. This is disappointing because spermine is present in mammalian brains at levels comparable to spermidine and it is a good substrate for SAT1. The spermine level in cerebral cortex of these subjects may be quantified by the development of a different GC-MS method specifically designed to measure this polyamine. 
In addition to our inability to properly quantify spermine, other limitations are present in this study. As mentioned above, we used subjects from a homogeneous population, which may prevent us from extending our results to other populations. In addition, this method cannot distinguish between free and bound polyamines. The majority of polyamines are conjugated with other molecules in the cell to fulfill the diversified functions of polyamines (Gugliucci, 2004). Third, the brain tissue used for this study comprised both neuronal and glial cells. Although polyamines are present in both neurons and glia, they appear to be concentrated in astroglial cells (Laube and Veh, 1997). Given recent evidence suggesting astroglial dysfunction in major depression and suicide (Banasr et al, 2008; Ernst et al, 2009; Rajkowska and Miguel-Hidalgo, 2007) future experiments should quantify polyamine levels in different brain cell populations.

Taken together, our current findings of elevated putrescine and spermidine levels in suicide completers with a history of major depression provide evidence for important consequences of the downregulation of SAT1 observed in previous studies, and may indicate that stress responses may be altered in these individuals.

\section{ACKNOWLEDGEMENTS}

We thank Carla Himmelman for technical assistance. The Quebec Suicide Brain Bank is supported in part by the Fonds de la Recherche en Santé du Québec (FRSQ) through the Réseau québecois de recherche sur le suicide. This work was supported by the Canadian Institute of Health Research (CIHR) MOP 79253. GT is an FRSQ chercheur boursier.

\section{DISCLOSURE}

The authors declare no conflict of interest.

\section{REFERENCES}

Banasr M, Chowdhury GM, Terwilliger R, Newton SS, Duman RS, Behar KL et al (2008). Glial pathology in an animal model of depression: reversal of stress-induced cellular, metabolic and behavioral deficits by the glutamate-modulating drug riluzole. Mol Psychiatry print copy in press (originally published online 30 September 2008, at http://dx.doi.org/10.1038/mp.2008.106).

Barron S, Mulholland PJ, Littleton JM, Prendergast MA (2008). Age and gender differences in response to neonatal ethanol withdrawal and polyamine challenge in organotypic hippocampal cultures. Alcohol Clin Exp Res 32: 929-936.

Bastida CM, Cremades A, Castells MT, Lopez-Contreras AJ, LopezGarcia C, Sanchez-Mas J et al (2007). Sexual dimorphism of ornithine decarboxylase in the mouse adrenal: influence of polyamine deprivation on catecholamine and corticoid levels. Am J Physiol Endocrinol Metab 292: E1010-E1017.

Belle NA, Dalmolin GD, Fonini G, Rubin MA, Rocha JB (2004). Polyamines reduces lipid peroxidation induced by different prooxidant agents. Brain Res 1008: 245-251.

Bence AK, Rogers DT, Worthen DR, Fu M, Littleton JM, Crooks PA (2000). Aminoanthraquinones as novel ligands at the polyamine binding site on the N-methyl-D-aspartate receptor complex. Bioorg Med Chem Lett 10: 2621-2623.

Bennett M (2009). Positive and negative symptoms in schizophrenia: the NMDA receptor hypofunction hypothesis, neur-
egulin/ErbB4 and synapse regression. Aust N Z J Psychiatry 43: 711-721.

Bird ED, Vonsattel JP (1993). The development of a brain bank. J Neural Transm Suppl 39: 17-23.

Bolkenius FN, Seiler N (1981). Acetylderivatives as intermediates in polyamine catabolism. Int J Biochem 13: 287-292.

Carlson MD, Penney Jr JB, Young AB (1993). NMDA, AMPA, and benzodiazepine binding site changes in Alzheimer's disease visual cortex. Neurobiol Aging 14: 343-352.

Casero RA, Pegg AE (2009). Polyamine catabolism and disease. Biochem J 421: 323-338.

Chang EH, Savage MJ, Flood DG, Thomas JM, Levy RB, Mahadomrongkul V et al (2006). AMPA receptor downscaling at the onset of Alzheimer's disease pathology in double knockin mice. Proc Natl Acad Sci USA 103: 3410-3415.

Chen GG, Turecki G, Mamer OA (2009). A quantative GC-MS method for three major polyamines in post-mortem brain cortex. J Mass Spectrom 44: 1203-1210.

Choi MH, Kim KR, Chung BC (2000). Determination of hair polyamines as N-ethoxycarbonyl-N-pentafluoropropionyl derivatives by gas chromatography-mass spectrometry. J Chromatogr A 897: 295-305.

Dumais A, Lesage AD, Lalovic A, Seguin M, Tousignant M, Chawky $\mathrm{N}$ et al (2005). Is violent method of suicide a behavioral marker of lifetime aggression? Am J Psychiatry 162: 1375-1378.

Ernst C, Deleva V, Deng X, Sequeira A, Pomarenski A, Klempan T et al (2009). Alternative splicing, methylation state, and expression profile of tropomyosin-related kinase B in the frontal cortex of suicide completers. Arch Gen Psychiatry 66: 22-32.

Ferioli ME, Pinotti O, Pirona L (1999). Gender-related differences in polyamine oxidase activity in rat tissues. Amino Acids 17: 139-148.

Fiori LM, Turecki G (2008). Implication of the polyamine system in mental disorders. $J$ Psychiatry Neurosci 33: 102-110.

First MB, Gibbon M, Spitzer RL (2001). Structured Clinical Interview for DSM-IV-TR Axis I Disorders, Research Version, Patient Edition with Psychotic Screen (SCID-I/P). New York State Psychiatric Institute: New York.

Freed WJ, Dillon-Carter O, Kleinman JE (1993). Properties of [3H]AMPA binding in postmortem human brain from psychotic subjects and controls: increases in caudate nucleus associated with suicide. Exp Neurol 121: 48-56.

Genedani S, Saltini S, Benelli A, Filaferro M, Bertolini A (2001). Influence of SAMe on the modifications of brain polyamine levels in an animal model of depression. Neuroreport 12: 3939-3942.

Gilad GM, Gilad VH (2002). Stress-induced dynamic changes in mouse brain polyamines. Role in behavioral reactivity. Brain Res 943: 23-29.

Gilad GM, Gilad VH (2003). Overview of the brain polyaminestress-response: regulation, development, and modulation by lithium and role in cell survival. Cell Mol Neurobiol 23: 637-649.

Gilad GM, Gilad VH, Casanova MF, Casero Jr RA (1995). Polyamines and their metabolizing enzymes in human frontal cortex and hippocampus: preliminary measurements in affective disorders. Biol Psychiatry 38: 227-234.

Gilad GM, Gilad VH, Wyatt RJ (1992). Polyamines modulate the binding of GABAA-benzodiazepine receptor ligands in membranes from the rat forebrain. Neuropharmacology 31: 895-898.

Gilad VH, Halperin R, Chen-Levy Z, Gilad GM (2002). Cyclic changes of plasma spermine concentrations in women. Life Sci 72: 135-141.

Groc L, Choquet D (2006). AMPA and NMDA glutamate receptor trafficking: multiple roads for reaching and leaving the synapse. Cell Tissue Res 326: 423-438.

Gugliucci A (2004). Polyamines as clinical laboratory tools. Clin Chim Acta 344: 23-35. 
Guipponi M, Deutsch S, Kohler K, Perroud N, Le Gal F, Vessaz M et al (2008). Genetic and epigenetic analysis of SSAT gene dysregulation in suicidal behavior. $A m \mathrm{~J}$ Med Genet $B$ Neuropsychiatr Genet 150B: 799-807.

Halene TB, Ehrlichman RS, Liang Y, Christian EP, Jonak GJ, Gur TL et al (2009). Assessment of NMDA receptor NR1 subunit hypofunction in mice as a model for schizophrenia. Genes Brain Behav 8: 661-675.

Igarashi K, Hara K, Watanabe Y, Hirose S, Takeda Y (1975). Polyamine and magnesium contents and polypeptide synthesis as a function of cell growth. Biochem Biophys Res Commun 64: 897-904.

Igarashi K, Kashiwagi K (2009). Modulation of cellular function by polyamines. Int J Biochem Cell Biol (in press) (originally published online 9 July 2009, at http://dx.doi.org/10.1016/j.biocel. 2009.07.009).

Ireland DR, Abraham WC (2009). Mechanisms of group I mGluRdependent long-term depression of NMDA receptor-mediated transmission at Schaffer collateral-CA1 synapses. J Neurophysiol 101: 1375-1385.

Jensen LS, Bolcho U, Egebjerg J, Stromgaard K (2006). Design, synthesis, and pharmacological characterization of polyamine toxin derivatives: potent ligands for the pore-forming region of AMPA receptors. Chem Med Chem 1: 419-428.

Karssen AM, Her S, Li JZ, Patel PD, Meng F, Bunney Jr WE et al (2007). Stress-induced changes in primate prefrontal profiles of gene expression. Mol Psychiatry 12: 1089-1102.

Kashiwagi K, Pahk AJ, Masuko T, Igarashi K, Williams K (1997). Block and modulation of N-methyl-D-aspartate receptors by polyamines and protons: role of amino acid residues in the transmembrane and pore-forming regions of NR1 and NR2 subunits. Mol Pharmacol 52: 701-713.

Kelly L, Farrant M, Cull-Candy SG (2009). Synaptic mGluR activation drives plasticity of calcium-permeable AMPA receptors. Nat Neurosci 12: 593-601.

Kielland A, Heggelund P (2002). AMPA and NMDA currents show different short-term depression in the dorsal lateral geniculate nucleus of the rat. J Physiol 542: 99-106.

Klempan TA, Rujescu D, Merette C, Himmelman C, Sequeira A, Canetti L et al (2009). Profiling brain expression of the spermidine/spermine $\mathrm{N}(1)$-acetyltransferase 1 (SAT1) gene in suicide. Am J Med Genet B Neuropsychiatr Genet 150B: 934-943.

Laube G, Veh RW (1997). Astrocytes, not neurons, show most prominent staining for spermidine/spermine-like immunoreactivity in adult rat brain. Glia 19: 171-179.

Li L, Hara K, Liu J, Yu Y, Gao L, Wang Y et al (2008). Rapid and simultaneous determination of hair polyamines as N-heptafluorobutyryl derivatives by gas chromatography-mass spectrometry. J Chromatogr B Analyt Technol Biomed Life Sci 876: $257-260$.

Li R, Dozmorov M, Hellberg F, Tian Y, Jilderos B, Wigstrom H (2004). Characterization of NMDA induced depression in rat hippocampus: involvement of AMPA and NMDA receptors. Neurosci Lett 357: 87-90.

Loschmann PA, Wullner U, Heneka MT, Schulz JB, Kunow M, Wachtel $\mathrm{H}$ et al (1997). Differential interaction of competitive NMDA and AMPA antagonists with selective dopamine D-1 and D-2 agonists in a rat model of Parkinson's disease. Synapse 26: 381-391.

Lovaas E, Carlin G (1991). Spermine: an anti-oxidant and anti-inflammatory agent. Free Radic Biol Med 11: 455-461.

Mai JK, Paxinos G, Voss T (2007). Atlas of the Human Brain. Academic Press: New York.

Marton LJ, Pegg AE (1995). Polyamines as targets for therapeutic intervention. Annu Rev Pharmacol Toxicol 35: 55-91.

Masuko T, Kusama-Eguchi K, Sakata K, Kusama T, Chaki S, Okuyama $S$ et al (2003). Polyamine transport, accumulation, and release in brain. J Neurochem 84: 610-617.
Nolte J (2002). The Human Brain: An Introduction to Its Functional Neuroanatomy. Mosby: St Louis.

Nowak G, Szewczyk B, Sadlik K, Piekoszewski W, Trela F, Florek E et al (2003). Reduced potency of zinc to interact with NMDA receptors in hippocampal tissue of suicide victims. Pol J Pharmacol 55: 455-459.

O'Neill MJ, Witkin JM (2007). AMPA receptor potentiators: application for depression and Parkinson's disease. Curr Drug Targets 8: 603-620.

Paik MJ, Lee KA, Park CS, Ahn YH, Lee G, Jeong R et al (2007). Pattern recognition analysis of polyamines in the plasma of rat models with adenovirus infection. Clin Chim Acta 380: 228-231.

Paik MJ, Lee S, Cho KH, Kim KR (2006). Urinary polyamines and $\mathrm{N}$-acetylated polyamines in four patients with Alzheimer's disease as their N-ethoxycarbonyl-N-pentafluoropropionyl derivatives by gas chromatography-mass spectrometry in selected ion monitoring mode. Anal Chim Acta 576: 55-60.

Pegg AE (2009). Mammalian polyamine metabolism and function. IUBMB Life 61: 880-894.

Rajkowska G, Miguel-Hidalgo JJ (2007). Gliogenesis and glial pathology in depression. CNS Neurol Disord Drug Targets 6: 219-233.

Ramchand CN, Das I, Gliddon A, Hirsch SR (1994). Role of polyamines in the membrane pathology of schizophrenia. A study using fibroblasts from schizophrenic patients and normal controls. Schizophr Res 13: 249-253.

Rao VR, Finkbeiner S (2007). NMDA and AMPA receptors: old channels, new tricks. Trends Neurosci 30: 284-291.

Rock DM, Macdonald RL (1995). Polyamine regulation of N-methyl-D-aspartate receptor channels. Annu Rev Pharmacol Toxicol 35: 463-482.

Ryan B, Musazzi L, Mallei A, Tardito D, Gruber SH, El Khoury A et al (2009). Remodelling by early-life stress of NMDA receptor-dependent synaptic plasticity in a gene-environment rat model of depression. Int $J$ Neuropsychopharmacol 12: 553-559.

Sanderson DJ, Good MA, Seeburg PH, Sprengel R, Rawlins JN, Bannerman DM (2008). The role of the GluR-A (GluR1) AMPA receptor subunit in learning and memory. Prog Brain Res 169: 159-178.

Seiler N, Atanassov CL (1994). The natural polyamines and the immune system. Prog Drug Res 43: 87-141.

Seiler N, Raul F (2005). Polyamines and apoptosis. J Cell Mol Med 9: 623-642.

Seillier A, Giuffrida A (2009). Evaluation of NMDA receptor models of schizophrenia: divergences in the behavioral effects of sub-chronic PCP and MK-801. Behav Brain Res 204: 410-415.

Sequeira A, Gwadry FG, Ffrench-Mullen JM, Canetti L, Gingras Y, Casero Jr RA et al (2006). Implication of SSAT by gene expression and genetic variation in suicide and major depression. Arch Gen Psychiatry 63: 35-48.

Sequeira A, Klempan T, Canetti L, ffrench-Mullen J, Benkelfat C, Rouleau GA et al (2007). Patterns of gene expression in the limbic system of suicides with and without major depression. Mol Psychiatry 12: 640-655.

Sohn HS, Park YN, Lee SR (2002). Effect of immobilization stress on brain polyamine levels in spontaneously hypertensive and Wistar-Kyoto rats. Brain Res Bull 57: 575-579.

Stromgaard K, Mellor I (2004). AMPA receptor ligands: synthetic and pharmacological studies of polyamines and polyamine toxins. Med Res Rev 24: 589-620.

Svinarev VI (1986). Polyamine studies of schizophrenia patients. Vrach Delo 12: 88-89.

Szewczyk B, Poleszak E, Sowa-Kucma M, Wrobel A, Slotwinski S, Listos J et al (2009). The involvement of NMDA and AMPA receptors in the mechanism of antidepressant-like action of zinc in the forced swim test. Amino Acids print copy in press 
Putrescine and spermidine in the suicide brain GG Chen et al

(originally published online 3 December 2009, at http:// dx.doi.org/10.1007/s00726-009-0412-y).

Takano K, Ogura M, Nakamura Y, Yoneda Y (2005). Neuronal and glial responses to polyamines in the ischemic brain. Curr Neurovasc Res 2: 213-223.

Tzschentke TM (2002). Glutamatergic mechanisms in different disease states: overview and therapeutical implications - an introduction. Amino Acids 23: 147-152.

Velloso NA, Dalmolin GD, Gomes GM, Rubin MA, Canas PM, Cunha RA et al (2009). Spermine improves recognition memory deficit in a rodent model of Huntington's disease. Neurobiol Learn Mem 92: 574-580.
Wallace HM, Fraser AV, Hughes A (2003). A perspective of polyamine metabolism. Biochem J 376: 1-14.

Wang HY, Stucky A, Liu J, Shen C, Trocme-Thibierge C, Morain P (2009). Dissociating beta-amyloid from alpha 7 nicotinic acetylcholine receptor by a novel therapeutic agent, S 24795, normalizes alpha 7 nicotinic acetylcholine and NMDA receptor function in Alzheimer's disease brain. J Neurosci 29: 10961-10973.

Zomkowski AD, Santos AR, Rodrigues AL (2006). Putrescine produces antidepressant-like effects in the forced swimming test and in the tail suspension test in mice. Prog Neuropsychopharmacol Biol Psychiatry 30: 1419-1425. 